\title{
The Shock Hugoniot of Hydroxy-Terminated Polybutadiene
}

\author{
Y. Meziere, J. Akavhan, G.S. Stevens, J.C.F. Millett, N.K. Bourne. \\ *Royal Military College of Science, Cranfield University, Shrivenham, Swindon, \\ SN6 8LA. United Kingdom.
}

\begin{abstract}
The response of polymers to shock loading is becoming of increasing importance, both as binder systems in plastic -bonded explosives (PBXs) and as structural materials in their own right. In this paper, we report on the shock Hugoniot of hydroxy-terminated polybutadiene (HTPB), which is commonly used as a binder system in PBXs, but whose shock response has yet to be presented in the open literature. Results indicate that the shock velocity - particle velocity relationship is linear, similar to some but not all polymer based materials.
\end{abstract}

\section{INTRODUCTION}

The need to understand the shock response of polymeric materials to shock loading, both from a mechanical and microstructural standpoint is becoming of increasing interest. In particular, those polymers that find application as the binder phases in plastic-bonded explosives (PBXs) such as polychloro-trifluroethylene (Kel-F) and polyurethane based materials such as estane have received attention [1, 2]. However, the shock response of one polymer that has yet to be studied is hydroxy-terminated polybutadiene (HTPB). Whilst a number of studies have considered it as part of a composite system in PBXs and propellants [3], it's individual response to high-rate loading has not been considered. In contrast, its response to quasi-static loading rates has been examined. Wingborg [4] has shown that the mechanical properties of HTPB are influenced by the choice of hardener.For example, using the hardener dicyclohexylmethane 4,4'-diisocyanate $\left(\mathrm{H}_{12} \mathrm{MDI}\right)$ resulted in a material with a tensile strength of $c a .9 \mathrm{MPa}$, compared to $c a .4 \mathrm{GPa}$ when using the more usual isophorone diisocyanate (IPDI).
In addition to the IPDI hardener, most HTPB binders also contain additional chemicals such antioxidants and plasticizers which will also have an effect upon their mechanical response. Therefore, in this paper, we measure the Hugoniots of two HTPB compositions, one with a plastisizer (supplied by Royal Ordnance in the United Kingdom), and one without, manufactured by ourselves at the Royal Military College of Science. In a parallel paper, we have also recovered this second material for chemical and microstructural analysis [5].

\section{EXPERIMENTAL}

Both materials were cast as $10 \mathrm{~mm}$ plates onto 1 $\mathrm{mm}$ thick plates of either dural (aluminium alloy 6082-T6) or copper, to which manganin stress gauges (MicroMeasurements LM-SS-125CH-048) had previously been fixed. These were insulated from the metallic plates with $25 \mu \mathrm{m}$ mylar with a slow setting epoxy adhesive. HTPB 1was prepared by Royal Ordnance, Glascoed, to a proprietry composition. HTPB 2 was prepared in house to a similar composition but without the plasticizer. Once cured, an addition gauge was supported on the back of the target assemblies using a $12 \mathrm{~mm}$ block 
of polycarbonate. In this way, not only stress and particle velocity (through impedance matching), but timing information through known positions of both gauges would yield the shock velocity. Shock stresses were induced by the impact of $10 \mathrm{~mm}$ dural and copper flyer plates. Gauge records were converted to stress-time traces using the methods of Rosenberg et al [6]. Particle velocities $\left(u_{\mathrm{p}}\right)$ were determined using impedance matching. Specimen configurations and gauge placements are shown in figure 1 .

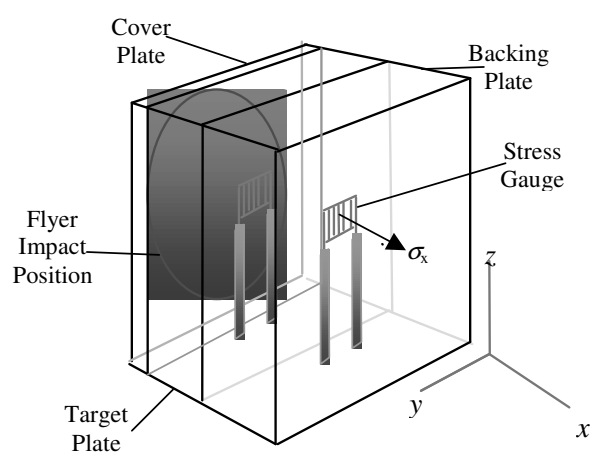

Figure 1. Specimen configuration and gauge placement.

HTPB 1 had a density $\left(\rho_{0}\right)$ of $0.85 \pm 0.01 \mathrm{~g} \mathrm{~cm}^{-3}$, and a longitudinal sound speed $\left(c_{\mathrm{L}}\right)$ of $1.46 \pm 0.03 \mathrm{~mm}$ $\mu \mathrm{s}^{-1}$, whilst HTPB 2 has a density of $1.06 \pm 0.01 \mathrm{~g}$ $\mathrm{cm}^{-3}$, and a sound speed of $1.43 \pm 0.03 \mathrm{~mm} \mu \mathrm{s}-1$. The sound speeds were measured using quartz transducers operating at $5 \mathrm{MHz}$, using a Panametrics 500PR pulse receiver.

\section{RESULTS AND DISCUSSION}

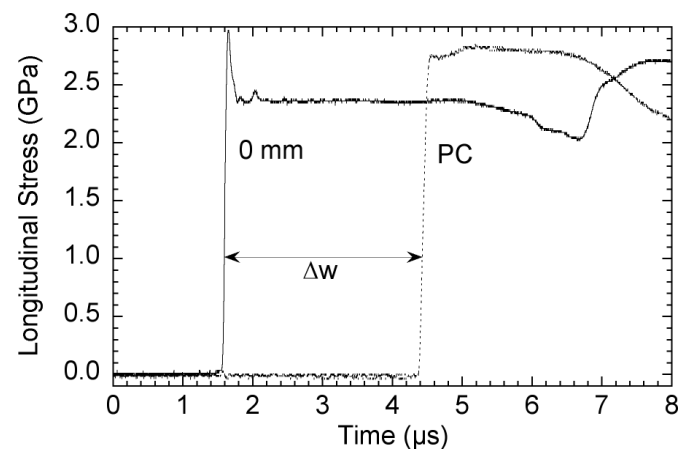

Figure 2. Gauge traces from plate impact experiment on HTPB1. Impact conditions are $10 \mathrm{~mm}$ copper flyer at
$769 \mathrm{~m} \mathrm{~s}^{-1} .0 \mathrm{~mm}$ - trace from gauge at $\mathrm{Cu} / \mathrm{HTPB}$ interface, $\mathrm{PC}$ - trace from $\mathrm{HTPB} /$ polycarbonate interface.

In figure 2, we present typical gauge records from a plate impact experiment upon hydroxyterminated polybutadiene, in this case, HTPB1.

A number of features in this figure are worthy of note. Firstly the trace labeled $0 \mathrm{~mm}$ records a sharp rise in signal, reaching a peak before settling to a steady value of $c a$. $2.4 \mathrm{GPa}$. This peak is due to the capacitive linking due to the fast-rising nature of the stress pulse and is discussed in more detail elsewhere [7]. The temporal spacing between the traces $(\Delta w)$, in combination with the known separation of the gauges is used to determine the shock velocity, $\left(U_{\mathrm{s}}\right)$. Finally, the trace labeled PC, that is from the gauge supported on the back of the HTPB with a polycarbonate block also shows a rapid rise in signal with a comparatively flat top. Due to the close impedance matching between polycarbonate, the epoxy adhesive and the gauge backing, the rise time is due to the thickness of the manganin gauge element, and thus the trace will be a good indication of the shape of the stress pulse as it travels through the sample. Even though the stress amplitude at $2.4 \mathrm{GPa}$ is high, there is no evidence of a break in slope that would indicate the presence of an HEL. Whilst the HEL of this and similar materials is not known, it would be expected to be relatively low in comparison to other polymers (PMMA for example has an HEL quoted at 0.75 $\mathrm{GPa}$ [8]). Also note that the top of the pulse is relatively flat, suggesting a linear relationship between shock velocity and particle velocity. This is in contrast to PMMA [8], where a pronounced rounding of the pulse was observed above the HEL, where the $U_{\mathrm{s}}-u_{\mathrm{p}}$ curve was also seen to be nonlinear due to the high rate sensitivity of the material.

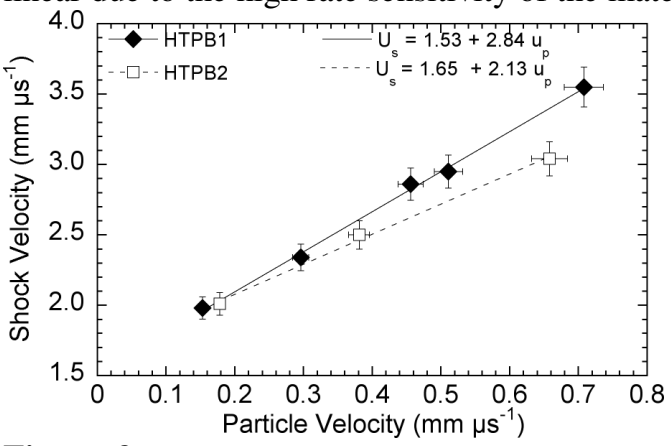

Figure 3. Shock Hugoniot of HTPB in shock velocity $\left(U_{\mathrm{s}}\right)$ - particle velocity $\left(u_{\mathrm{p}}\right)$ space. 
This issue is explored further in figure 3 . The plots are both materials are broadly similar, in that both show a linear response, as was suggested previously. The values of the shock parameters $c_{0}$ and $S$ are different for each material. In particular, the value of $c_{0}$ in HTPB2 is higher than in HTPB1. This suggests that the compressibility of the latter is greater. Given that this material has had an addition of plasticizer, which will have the effect of increasing the mechanical compliance, this observation from the shock velocities makes sense.

One feature that is common to both materials concerns the relationship of the measured longitudinal sound speeds to the values of $c_{0}$ determined from measurements of the shock velocity. In most metallic systems, for example copper or tantalum, the value of $c_{0}$ corresponds to the ambient pressure bulk sound speed [9]. However, in both HTPBs investigated here, $c_{0}$ is greater than the measured ambient longitudinal sound speed. This is a feature that has been observed both by ourselves, for example in polyether ether ketone [10], an epoxy resin [11] and polychloroprene [12], and others, for example Carter and Marsh [13]. Indeed in that work, the authors investigated the shock response of 22 different polymers, and in all but four was it observed that $c_{0}$ was greater than $c_{\mathrm{L}}$. Therefore, we can explain why no elastic precursor was observed the trace labeled PC in figure 2. The results from figure 3 show that the shock wave will always be faster than the elastic precursor, hence it will not be observed.

The relationship between shock velocity and particle velocity has been used to determine the shock stress $\left(\sigma_{\mathrm{x}}\right)$ through the relation,

$\sigma_{x}=\rho_{0} U_{s} u_{p}$

Note that this does not take into account the strength of the material. However, comparison with the measured stresses from the gauges is a useful exercise, giving insights into the materials response to shock loading. The results are presented in figure 4 .

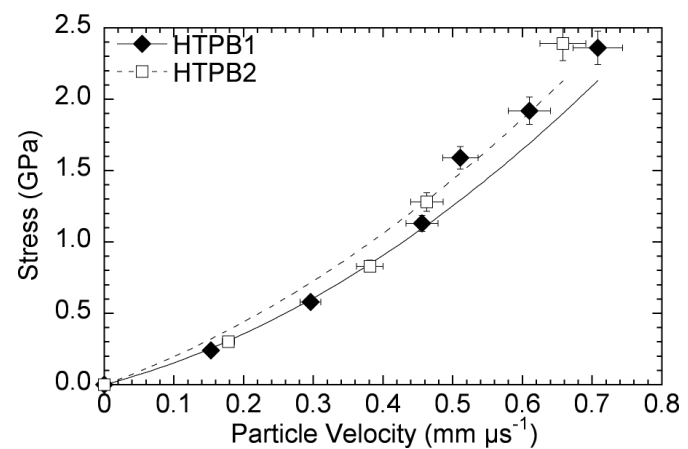

Figure 4. Shock Hugoniots of HTPB

The measured values of stress from both materials are effectively identical to each other, in contrast to the shock velocity plots. The comparison of the stresses calculated from equation 1 (using the relevant values of density, $c_{0}$ and $S$ ) to the measured stresses in both materials is more revealing. In both materials, the agreement is good at lower stresses, but at higher levels, the curves diverge, with the measured stresses being the higher. However, as we have already stated, equation 1 does not allow for the materials strength and its variation with impact strength. The longitudinal stress generated during shock loading can be expressed as a function of the hydrostatic pressure, $P$ and the materials shear strength, $\tau$, thus,

$\sigma_{x}=P+\frac{4}{3} \tau$

Therefore, failure to take the effects of shear strength into account in this calculation could result in differences between calculated and measured stresses. We would point out that the 'stress' calculated from equation 1 is the hydrodynamic response of the material. whilst $P$ is the hydrostatic pressure, and thus the two will be slightly different. Therefore, while we would not suggest that values of the shear strength could be determined from a combination of equations 1 and 2, differences between the measured Hugoniot stress and equation 1 will still reveal overall trends in materials response. Similar behaviour has been noted in other materials, including polyether ether ketone (PEEK) [10] and epoxy based resins [14], where these differences were correlated with an increasing shear strength with impact stress amplitude, determined from experimental measurements [15]. More 
interestingly, we have also noticed in materials where the measured and calculated stresses agree (for example polychloroprene [12]), the measured shear strength was observed to remain at a constant level with increasing impact stress [16], therefore supporting the hypothesis that the observed differences in figure 4 indicate that HTPB has a positive dependence of shear strength on the impact stress.

\section{CONCLUSIONS}

The shock response of two compositions of hydroxy-terminated polybutadiene has been determined in terms of the shock velocity, shock stress and particle velocity. Results in both materials show a linear relationship between us and up, with the pure material having a greater value of $c_{0}$. This would appear consistent with the fact that this material has no added plasticizer, which would have the effect of reducing the compressibility of the material. The Hugoniots in terms of stress and particle velocity in both materials are similar, but comparisons of measured and calculated stresses show differences at higher stresses, suggesting that these materials have an increasing shear strength with impact stress. Further work is in progress to determine if this is correct.

\section{ACKNOWLEDGMENTS}

We would like to thank Dr. Ian Murray and Dr. Ron Hollands of Royal Ordnance, Glascoed for provision of samples. We are also grateful to Gary Cooper, Matt Eatwell and Paul Dicker of RMCS for technical assistance.

\section{REFERENCES}

1. Anderson, M.U., in Shock Compression of Condensed Matter - 1991, S.C. Schmidt, et al., Editors. 1992, Elsevier: Amsterdam. p. 875.

2. Bourne, N.K. Gray III, G.T., in Plasticity 99: Constitutive and Damage Modeling of Inelastic Deformation and Phase Transformation, A.S. Khan, Editor. 1998, Neat Press: Fulton, Maryland. p. 619.

3. Sutherland, G.T., Forbes, J.W., Lemar, E.R., Ashwell, K.D., Barker, R.N., in High Pressure Science and
Technology 1993, S.C. Schmidt, et al., Editors. 1994, American Institute of Physics: New York. p 1381

4. Wingborg, N., Polymer Testing, 2002. 21283.

5. Akavhan, J., Millett, J.C.F., Bourne, N.K. in These Proceedings

6. Rosenberg, Z., Yaziv, D., Partom, Y. J. Appl. Phys., 1980. 513702.

7. Bourne, N.K., Rosenberg, Z. Meas. Sci. Technol., 1997. 8570.

8. Barker, L.M., Hollenbach, R.E. J. Appl. Phys., 1970. 414208.

9. Marsh, S.P., LASL Shock Hugoniot data. 1980, Los Angeles: University of California Press. Los Angeles 10. Millett, J.C.F., Bourne, N.K., Gray III, G.T. J. Appl. Phys., 2003 Submitted.

11. Millett, J.C.F., Bourne, N.K., Barnes, N.R. J. Appl. Phys., 2002. 926590.

12. Millett, J.C.F. Bourne, N.K.. J.Appl. Phys., 2001. 89 2576.

13. Carter, W.J., Marsh, S.P. Hugoniot equation of state of polymers. 1995, Los Alamos National Laboratory. LA13006-MS

14. Barnes, N., Millett, J.C.F., Bourne, N.K., in Shock Compression of Condensed Matter - 2001, M.D. Furnish, N.N. Thadhani, Y. Horie Editors. 2002. American Institute of Physics: Melville, NY.p.135

15. Bourne, N.K., Millett, J.C.F., Barnes, N., Belcher I. in Shock Compression of Condensed Matter - 2001, M.D. Furnish, N. Thadhani, and Y. Horie, Editors. 2002, American Institute of Physics: Melville, NY. 649.

16. Bourne, N.K. Millett, J.C.F. P Roy. Soc. Lond. A, 2002. 459567. 